\title{
Triggering and modulation of the host-parasite interplay by Echinococcus multilocularis: a review
}

\author{
N. MEJRI, A. HEMPHILL and B. GOTTSTEIN* \\ Institute of Parasitology, University of Bern, Laenggass-Strasse 122, CH-3001 Bern, Switzerland \\ (Received 4 August 2009; revised 11 September 2009; accepted 14 September 2009; first published online 7 December 2009)
}

\begin{abstract}
SUMMARY
As more facts emerge regarding the ways in which E. multilocularis-derived molecules trigger the host immune response and modulate the host-parasite interplay, it becomes possible to envisage how the parasite can survive and proliferate in its intermediate host, while in other hosts it dies out. Through effects on cells of both the innate and adaptive arms of the immune response, E. multilocularis can orchestrate a range of outcomes that are beneficial not only to the parasite, in terms of facilitating its intrahepatic proliferation and maturation, and thus life cycle over all, but also to its intermediate host, in limiting pathology. The present review deals with the role of metacestode surface molecules as well as excretory/secretory $(\mathrm{E} / \mathrm{S})$ metabolic products of the parasite in the modulation of the host responses such as to optimize its own survival.
\end{abstract}

Key words: Echinococcus multilocularis, alveolar echinococcosis, immunology, metabolites, immune modulation.

\section{INTRODUCTION}

Alveolar echinococcosis (AE) is one of the most severe helminthic diseases affecting humans. Infection is acquired upon ingestion of eggs of the fox tapeworm Echinococcus multilocularis. As a result, the metacestode (larval) stage of the parasite grows as a tumour-like tissue in the liver of its host. At a later stage, metastasis formation in adjacent and peripheral sites may cause detrimental obstruction of the respectively affected organs. Late diagnosis and nontreatment may result in case fatality. The natural intermediate hosts involved in the life cycle of the parasite, however, include predominantly small rodents. Similarly, humans contract AE accidentally, but with no subsequent involvement of the definitive hosts. Thus, the laboratory mouse is an excellent model to study the host-parasite interplay. Experimental intraperitoneal inoculation of metacestodes is referred to as secondary infection. In the peritoneal cavity of AE-infected mice, inter-visceral tumourlike growth of the metacestode overcomes the immune system and subsequently establishes a chronic phase of infection, which persists approximately between 2-6 months p.i. Through effects on cells of both the innate and adaptive arms of the immune response, the parasite can orchestrate a range of outcomes that are beneficial not only for metacestode establishment, but also in terms of facilitating its proliferation and maturation. In addition, the

* Corresponding author: Institute of Parasitology, University of Bern, Laenggass-Strasse 122, CH-3001, Bern, Switzerland. Tel: +413163124 18. Fax: +413163124 77. E-mail: bruno.gottstein@ipa.unibe.ch complex host-parasite interaction leads to only limited pathology. Thus, a higher survival potential for both host and parasite is achieved.

In the host-parasite interplay, metacestode surface molecules as well as excretory/secretory (E/S) metabolic products are considered to function as important key players (reviewed in Gottstein and Hemphill, 2008). The intraperitoneal murine infection model of AE offers the opportunity to study the direct effect of metabolic metacestode molecules on periparasitic peritoneal cells, including especially dendritic cells (DCs), but also other immunologically relevant populations such as macrophages (MØ), lymphocytes and other (inflammatory) cells that will play a significant role in the putative control of (or respective failure to control) the metacestode proliferation, and thus triggering of disease development.

In $\mathrm{AE}$, the involvement of cellular immunity in controlling the infection is strongly suggested by studies in immunocompromised hosts. Immunodeficient athymic nude (Playford and Kamiya, 1992) and SCID mice (Playford et al. 1992) as well as HIV-co-infected patients (Sailer et al. 1997; Zingg et al. 2004) exhibited high susceptibility to infection and disease, thus suggesting that the cell mediated immune response plays an important role in suppressing larval growth.

\section{E. MULTILOCULARIS METACESTODE METABOLITES}

The E. multilocularis metacestode actively secretes or expresses molecules that putatively have potent effects on the immune system of the murine host. 
The production of these molecules and their chemical compositions might depend on the stage of the parasite (oncosphere, early vesicle or fully mature metacestode). However, little is known about biological effector molecules arising metabolically or somatically from the intrahepatic stages of the metacestode, although various $E$. multilocularis antigens, their epitopes and respective genes have been characterized. Among the main antigens described, a major carbohydrate named Em2 (G11) localizes on the surface of the laminated layer of the metacestode (Gottstein et al. 1992). Another polysaccharidecontaining antigen $\mathrm{C}$ has been isolated and characterized from crude metacestode extract (Sato and Furuya, 1994). Similar investigations have yielded the finding of EmP2 (Ingold et al. 1998), a high molecular mass glycan as a part of the major structural elements of the laminated layer (Ingold et al. 2000). Biological activity of a high molecular mass carbohydrate molecule, called Em492, was demonstrated by Walker et al. (2004), from which they concluded that the Em492-antigen could be one of the factors contributing to immunosuppressive events that occur at the host-parasite interface. Another neutral glycosphingolipid has been identified as suppressor of human PBMCs proliferation following stimulation by phytohemagglutinin (Persat et al. 1992, 1996). Structure determination of this glycosphingolipid fraction had revealed that it belongs to the neogala series $(\mathrm{Gal} \beta 1 \rightarrow 6 \mathrm{Gal})$. Huelsmeier and co-workers (2002) had then isolated novel mucin-type glycoforms from the metacestode of E. multilocularis, and these glycoforms contained mucin-type core-I type and core-II type structures that were further diversified by addition of GlcNAc or Gal residues. Recently, Koizumi et al. (2009) reported on the synthesis of the glycan portions of a glycoprotein antigen of E. multilocularis in order to elucidate the interactions between oligosaccharides and sera of $\mathrm{AE}$ by enzyme-linked immunosorbent assay (ELISA). Stereocontrolled synthesis of branched tri-, tetra-, and pentasaccharides displaying a $\mathrm{Gal} \beta 1 \rightarrow 3 \mathrm{GalNAc}$ core in the glycan portion of the glycoprotein antigen was achieved, which may become an interesting tool for further studies on their putative biological function.

With regard to metabolized proteins, an E. multilocularis protoscolex-associated antigen of $62 \mathrm{kDa}$ (Auer et al. 1988), two 70 and $90 \mathrm{kDa}$ proteins (Korkmaz et al. 2004), and several recombinant E. multilocularis-proteins (such as antigen II/3 (Vogel et al. 1988) and its subfragments II/3-10 (Müller et al. 1989) and Em18 (Ito et al. 1995), EM10 (Frosch et al. 1991)), have all been published and discussed in view of a potential biological role. However, these antigens were mainly used to investigate respective immune responses with emphasis on immunodiagnosis of $\mathrm{AE}$, and their biological functions have not been appropriately studied. Siles and coworkers (1998) identified and cloned a 14-3-3gene of E. multilocularis, which appeared to play a key role in basic cellular events related to cellular proliferation, including signal transduction, cellcycle control, cell differentiation and cell survival (Siles et al. 1998; Siles and Gottstein, 2003). E. multilocularis rec14-3-3 protein, used as a vaccine, was highly protective $(97 \%)$ against primary challenge infection with E. multilocularis eggs (Siles et al. 2003). Gauci et al. (2002) identified an E. multilocularis cDNA encoding an antigen (designated EM95), which demonstrated that a respective EM95 recombinant protein could be used to induce significant levels of protection against challenge infection with $E$. multilocularis eggs in mice. In a similar context, Kouguchi et al. (2007) identified a cDNA clone, designated as EMY162 that encoded a putatively secreted protein. EMY162 shared structural features with the EM95 antigen, e.g. $31 \%$ amino acid sequence identity to EM95. RT-PCR analysis revealed that EMY162 gene expression was significantly higher than EM95 at each life cycle stage. Recombinant EMY162 antigen induced a significant level of host protection $(74 \cdot 3 \%)$ upon experimental challenge infection with $E$. multilocularis eggs in mice.

HOST RESPONSE TO METABOLITES AND SOMATIC PARASITE MOLECULES OF E. MULTILOCULARIS

In murine infections with $E$. multilocularis, the involvement of cellular immunity in controlling the infection is strongly suggested by the intense granulomatous infiltration observed in the periparasitic area of lesions (Bresson-Hadni et al. 1990; Emery et al. 1996). E. multilocularis appears to induce skewed Th2-responses (Emery et al. 1996). Based on in vitro and in vivo studies, Th2 dominated immunity was associated with increased susceptibility to disease, while Th1 cell activation through IL-12 (Emery et al. 1996), IFN $\gamma$ (Jenne et al. 1998; Liance et al. 1998), TNF $\alpha$ (Amiot et al. 1999) and IFN $\alpha$ (Godot et al. 2003) was suggested to induce protective immunity in AE (Emery et al. 1998; Vuitton, 2003). The intense periparasitic granulomatous infiltration indicates an intense host-parasite interaction, and the involvement of cellular immunity in control of the metacestode growth kinetics is strongly suggested by experiments carried out in $\mathrm{T}$ cell-deficient mouse strains (Dai et al. 2004). At the time of initial encounter with its murine host, the metacestode might modulate the immune response; the changes that it induces are dynamic and depend on the stage of development, e.g. ranging from oncosphere, to early stage vesicles up to a fully mature and fertile metacestode. Dendritic cells (DCs) and macrophages (MØs) are among the first cells encountered by the parasite, which, by secreting and expressing certain molecules, has evolved mechanisms to suppress the 
major inflammatory and thus immunopathological pathway. Interaction of parasite metabolites with Toll-like receptors (TLRs) and C-type lectin receptors (CLRs) that are expressed largely, but not exclusively, on DCs and MØs is assumed to result in phenotypic changes and modification of the cytokine profiles produced by these cell types, but this has not yet been shown experimentally at the early postoncospheral stage of infection of murine AE.

\section{DENDRITIC CELLS AND MACROPHAGES (MØ)}

DCs, the most important antigen-presenting cells (APCs) in the initiation of a type 1 or type 2 immune response, in dependence of the nature of the antigen(s) (Foti et al. 2006), range among the first players in the elaboration of a specific immune response. In the frame of a Th1 immune orientation, it is largely accepted that DCs are activated mostly by bacterial or viral pathogens via Toll-like receptor (TLR) ligation to produce IL-12 and TNF- $\alpha$, both pro-inflammatory cytokines inducing a Th1 oriented response (Boonstra et al. 2003; Takeda et al. 2003). Th1 -associated DC activation by microbial products evokes rapid phenotypic changes, including upregulation of MHC class II, CD80, CD86 and CD40 (Reis e Sousa et al. 1999; Romagnoli et al. 2004). Thereafter, DCs have the ability to fully activate effector $\mathrm{T}$ cells. There is no mirror-image signature of cytokine and surface ligands that DCs express to stimulate Th2 differentiation. However, exposure of DCs to some helminthic antigens, including the products of filarial Acanthocheilonema viteae (ES-62), Schistosoma mansoni soluble egg antigen (SEA), and the schistosome-associated glycan lactoN-ficopentaose III (LNFPIII), was found to pulse DCs to prime CD4 + T cells into Th2 type cells, and this occurred in the absence of increased MHC class II expression and co-stimulation molecule up-regulation (Whelan et al. 2000; MacDonald et al. 2001; Thomas et al. 2003). Ingold et al. (2000) had revealed the presence of high molecular mass glycans that form the major structural elements on the laminated layer of the metacestode of E. multilocularis. Whether exposure of DCs to these AE-glycans would pulse them to prime naïve CD4 $+\mathrm{T}$ into Th2 differentiated cells needs to be addressed.

Those helminth antigens mentioned above (ES-62, SEA, glycan LNFPIII) do not appear to induce DCs to produce IL-12 (MacDonald et al. 2001). Thus, the Th2 response could result as a default-pathway that occurs in the absence of IL-12 production (Sher et al. 2003). DCs did not display any new phenotype following stimulation with the respective parasite antigens. Thus DC-dependent Th2 immunity appeared to result from antigen presentation in the absence of DC activation and/or maturation (Maizels et al. 2004). Indeed, it has been previously shown that immature DCs did not mature upon exposure to unfractionated crude metacestode antigen of E. multilocularis (Maizels et al. 2004). DCs that can induce tolerance may need to be resistant to maturation-inducing factors (Morelli and Thomson, 2007). A primary early source of IL-4 is needed to drive the priming of naïve CD4 $+\mathrm{T}$ cells into differentiated Th2 type cells (Abbas et al. 1996; O’Garra, 1998). It has been shown earlier in several models of ecto- or endo-parasitic infections that IL-4 might be produced early by different cell types, including DCs and other cells such as keratinocytes, $\mathrm{T} \gamma \delta$, mast cells and basophils (Mbow et al. 1994; Falcone et al. 1996). Aumüller et al. (2004) used extracts from metacestodes of $E$. multilocularis to induce basophil degranulation, as well as the secretion of histamine, IL-4 and IL-13, in a dosedependent manner. They concluded that E. multilocularis induces a Th2 response upon IL-4 release from basophils.

Macrophages from AE-infected mice (AE-MØ) as APCs exhibited a reduced ability to present a conventional antigen (chicken ovalbumin, C-Ova) to specific responder lymph node $\mathrm{T}$ cells when compared to normal MØ from non-infected mice (Mejri and Gottstein, 2006). This obstructed activity in antigen presentation of AE-MØ appeared to trigger an unresponsiveness of $\mathrm{T}$ cells, which in turn led to the suppression of their clonal expansion during the chronic phase of AE infection. In a similar context it was shown that high periparasitic NO production by peritoneal exudate cells, mainly AE-MØs, also contributed to periparasitic immunosuppression (Dai and Gottstein, 1999; Andrade et al. 2004). Parasitederived molecules also interfered with antigen presentation and cell activation, leading to a mixed Th1/Th2-type response at the later stage of infection. This correlated with the marked depression of the cell mediated immune response that had been observed in chronic AE (Devouge and Ali-Khan, 1983; Kizaki et al. 1991, 1993).

\section{T AND OTHER CELLS}

Cells of the innate immune system are not the only targets of these immunomodulatory parasite-derived molecules. Endothelial cells (in the skin, lungs, intestine and liver) can also be induced to express and secrete anti-inflammatory mediators, such as IL-10 and prostaglandins (Zaccone et al. 2008). In this way, the parasite not only reduces its likelihood of elimination but can also minimize local host-tissue damage, with coincidental and paradoxical benefits for the host. By inducing functional changes in DCs and $M \varnothing_{\mathrm{s}}$, the metacestode can achieve important shifts in T cell subsets. An initial acute inflammatory Th1 response is subverted gradually to a Th2 response during the chronic phase of AE. Cytokines, such as IL-4, IL-5, IL-9 and IL-13, secreted largely 
by immune cell types in response to parasite antigens, not only down-modulate the Th1 response but can also promote parasite expulsion and tissue renewal and repair (Pennock and Grencis, 2006). The metacestode most likely achieves the Th2 expansion through the induction of regulatory cytokines, such as IL-10 and TGF- $\beta$ (Zhang et al. 2008). As mentioned above, in murine $\mathrm{AE}$, the host cell mediated immune response plays an important role in controlling the metacestode proliferation.

In the past decade, the Th1-Th2 paradigm has been revisited continually and alternative $\mathrm{T}$ cell lineages have been proposed. In particular, the recent discovery of the IL-17 cytokine family has added a new dimension to the balance of inflammation and tolerance during parasite infections. The presence of IL-17-secreting CD4 + T (Th17) lymphocytes correlates with high hepatic pathology in murine schistosomiasis (Rutitzky et al. 2005), which prompts a more detailed similar investigation in murine AE. Another member of the IL-17 cytokine family, IL-25 (or IL-17E), also has an important role in parasitic infections. Fallon et al. (2006) demonstrated that IL-25 was important for mounting an appropriate Th2 response to Nippostrongylus brasilensis, and also for efficient parasite clearance. The sources of IL-25 include activated Th2 cells, mast cells and a non-B non-T cells (Fort et al. 2001). IL-25 as a new player will have to be the focus of respective investigations in murine $\mathrm{AE}$, too.

\section{EOSINOPHILS}

One of the striking features observed in experimental murine $\mathrm{AE}$ (and also in naturally acquired $\mathrm{AE}$ of humans) is the absence of any eosinophilia. The mobilization of eosinophils is known to be a crucial immunological event that plays an important role in the host defence against helminths. Eotaxin, a CC-proinflammatory chemokine, is one of several described chemo-attractants for eosinophils. In addition, also IL-5 may mobilize these cells (Yamaguchi et al. 1988) but its role remains controversial. In many examples of nematode infections, eosinophilia is a marked characteristic, and eosinophils directly cause profound damage to the worm tegument, such as in Strongyloides ratti and in $T$. spiralis, in which a marked reduction of fertility and longevity was observed (Machado et al. 2005). On the other hand, IL-5 and eosinophils had no detectable effects on the infection with Mesocestoides corti, Hymenolepis diminuta and Fasciola hepatica (Ovington and Behm, 1997). An extravasation of eosinophils causing eosinophilia in the peritoneal cavity has been demonstrated to be beneficial for the host by causing damage to the immigrant immature Fasciola hepatica, resulting in the erosion of the tegumental syncytium (Burden et al. 1983). Eosinophils possess granules containing a variety of toxic molecules (major basic protein (MBP), peroxidase, neurotoxin, histaminase and others) which are active against many multicellular parasites, in particular helminths (Saraswathi et al. 2003). To elucidate the situation in experimental murine AE, we demonstrated that metacestode antigens (VF and $\mathrm{E} / \mathrm{S})$ exhibit proteolytic activity on eotaxin in vitro (Mejri and Gottstein, 2009). Inhibition of eotaxin activity may suppress the mobilization of eosinophils into the peritoneal cavity of intraperitoneally AEinfected mice. Eotaxin is considered as one of the main activator and chemo-attractant of resident eosinophils secreted principally by epithelial cells of the intestine (Mishra et al. 1999). A putative inhibition of granulocytic eosinophil infiltration may be relevant for parasite survival, as this type of cells is particularly important in the defence against helminths (Ovington and Behm, 1997). In experimental murine $\mathrm{AE}$, the detected eotaxin inactivation by $\mathrm{VF}$ and $\mathrm{E} / \mathrm{S}$ products may contribute to explain the absence of eosinophils within the peritoneal cavity of AE-secondary infected mice. Absent eosinophils thus may be a part of a series of events that maintain a low level of inflammation displayed within the peritoneal cavity of experimentally infected mice.

\section{FROM MURINE TO HUMAN AE}

The conventional course of $\mathrm{AE}$ as a disease in humans resembles strongly that of the naturally infected mouse, in that untreated AE will, in many but not all cases, finally lead to fatality. The first detection of naturally 'aborted' calcified liver lesions in E. multilocularis-infected persons (Godot et al. 2000; Gottstein et al. 2001) have indicated that not all infected individuals permit E. multilocularis metacestode development (Vuitton, 2003). That cell mediated immunological parameters play a crucial role also in human AE became clinically obvious when immunosuppressive status such as after liver transplantation (Bresson-Hadni et al. 2003) or during AIDS (Sailer et al. 1997; Zingg et al. 2004), resulted in a dramatically increased disease severity. Most studies so far have stressed a role for CD8 $+\mathrm{T}$ cells and for Interleukin-10 in the development disease susceptibility (Vuitton et al. 2003). A spontaneous secretion of IL-10 by PBMCs seemed to be the immunological hallmark of patients with progressive forms of AE. IL-10-induced inhibition of effector macrophages but also of antigenpresenting dendritic cells may be operating to protect the parasitic growth and survival (Vuitton et al. 2003). Susceptibility to infection in humans associates with predominantly TH2-related immunity (Wellinghausen et al. 1999), including IL-10 (Godot et al. 1997; 2000), IL-4 (Kilwinski et al. 1999), IL-5 (Sturm et al. 1995) production, especially during chronic stage of infection. Thus, in terms of Th polarization and associated cytokine expression, man 
and mouse appear to respond to infection quite similarly. Kocherscheidt et al. (2008) studied chemokine responses in $\mathrm{AE}$ patients at different states of infection (progressive, stable and cured AE). The production of $\mathrm{CC}$ and $\mathrm{CXC}$ chemokines which are associated with inflammation (MIP-1 alpha/CCL3, MIP-1 beta/CCL4, RANTES/CCL5 and GRO-alpha/CXCL1) was constitutively larger in all groups of AE patients than in controls (Kocherscheidt et al. 2008). A disparate cellular responsiveness was observed in all groups of AE patients to viable $E$. $m u l$ tilocularis vesicles; cluster 1 (GRO-alpha/CXCL1, MCP-3/CCL7, MCP-4/CCL13, TARC/CCL17, LARC/CCL20) and cluster 2 chemokines (PARC/ CCL18, MDC/CCL22, MIG/CXCL9) were downregulated, while cluster 3 chemokines (MIP-1 alpha/ CCL3, MIP-1 beta/CCL4, RANTES/CCL5) appeared up-regulated (Kocherscheidt et al. 2008). The fact that E. multilocularis metacestodes selectively suppressed cellular chemokine production in $\mathrm{AE}$ patients may constitute an immune escape mechanism which reduces inflammatory host responses, prevents tissue destruction and organ damage, but may also facilitate parasite persistence.

\section{FROM AE TO CE}

In tandem with $\mathrm{AE}$, the host response to infection with E. granulosus (cystic echinococcosis, CE) exhibits some similarities, but also striking dissimilarities. E. granulosus evokes an immune response, which is involved in the formation of a host-derived adventitious capsule. This often calcifies uniquely in the periphery of the cyst, one of the typical features found in imaging procedures, and a marked difference to AE. On differentiation into the hydatid cyst, mechanisms inhibiting complement activation on the cyst wall have been elucidated, contributing to the understanding of how the inflammatory response is controlled during CE. Similarly to AE, immunoregulatory events have been linked to the generation of $\mathrm{T}$ suppressor populations and to impairing the accessory action of macrophages in lymphoproliferative responses (Riley and Dixon, 1987). E. granulosus was also shown to be a polyclonal activator of $B$ cells inducing both transformation and differentiation, and the effect was thymus independent (Cox et al. 1989). The mechanism by which the hydatid cyst regulates potentially larvicidal effector mechanisms appeared to be based on the production of lymphokines suppressive for metacestode killing (Jenkins et al. 1990). Data obtained from experimental infections of E. granulosus supported the hypothesis that early IL-10, secreted by B cells in response to non-protein antigens, may favour parasite-survival and the establishment of a polarized type- 2 cytokine response (Baz et al. 2006). The coexistence of elevated quantities of interferon gamma (IFN-g), interleukin (IL)-4, IL-5, IL-6 and
IL-10 observed in most of CE patients supports Th1, Th17 and Th2 cell activation in CE. In particular, Th1 cell activation seemed to be more related to protective immunity, whereas patients with active and transitional cyst presented a rather mixed Th1/ Th2 and Th0 orientation (Rigano et al. 2004). The latter may be actively triggered by the parasite itself, as demonstrated by the fact that the hydatid cyst secretes and exposes numerous immunomodulatory molecules to the host's immune system, similar to AE (Siracusano et al. 2008).

\section{MODULATION OF HOST RESPONSE BY \\ E. MULTILOCULARIS METABOLITES}

The larval infection with E. multilocularis begins with the intrahepatic post-oncospheral development of a metacestode. In certain cases, an appropriate host immune response may inhibit parasite proliferation. Several lines of evidence obtained in vivo and in vitro indicate the important bio-protective role of the metacestode laminated layer (Gottstein et al. 2002). For instance, the laminated layer has been proposed to protect the germinal layer from nitric oxide produced by periparasitic macrophages and dendritic cells, and also to prevent immune recognition by surrounding $\mathrm{T}$ cells. On the other hand, the high periparasitic NO production by peritoneal exudate cells contributes to periparasitic immunosuppression (Dai and Gottstein, 1999; Andrade et al. 2004), explaining why iNOS-deficient mice exhibit a significantly lower susceptibility towards experimental infection (Dai et al. 2003).

Carbohydrate components of the laminated layer, such as $\operatorname{Em} 2(\mathrm{G} 11)$ and $\mathrm{Em} 492$, as well as other parasite metabolites yield immunomodulatory effects that allow the parasite to survive in the host, i.e. the $\mathrm{IgG}$ response to the $\mathrm{Em} 2(\mathrm{G} 11)$-antigen takes place independently of alpha-beta $+\mathrm{CD} 4+\mathrm{T}$ cells, and in the absence of interactions between CD40 and CD40 ligand (Dai et al. 2001). Such parasite molecules also interfere with antigen presentation and cell activation, leading to a mixed Th1/Th2-type response at the later stage of infection. Furthermore, Em492 (Walker et al. 2004) as a purified parasite metabolite suppresses ConA and antigen-stimulated splenocyte proliferation.

Interesting insights into immunomodulation by the parasite were obtained with regard to human AE. Hübner et al. (2006) examined the production of cytokines, chemokines and the expression of CD molecules on peripheral blood mononuclear cells (PBMC) from AE patients and healthy controls in response to $E$. multilocularis metacestode culture supernatant, viable metacestode vesicles and vesicle fluid antigen in vitro. After $48 \mathrm{~h}$ of co-culture, the antigens depressed the release of the proinflammatory cytokine interleukin (IL)-12 by PBMC. This effect was dose-dependent and a suppression of 
tumour necrosis factor (TNF)- $\alpha$ and IL-12 was observed even when PBMC were activated with lipopolysaccharide (LPS). Comparing proinflammatory cytokine release by AE patients and controls showed that the release of IL-12 and TNF- $\alpha$ was reduced in $\mathrm{AE}$ patients, which was accompanied by an increased number of $\mathrm{CD} 4+\mathrm{CD} 25+$ cells and a reduced release of the Th2 type chemokine CCL17 (thymus and activation regulated chemokine, TARC), suggesting an anti-inflammatory response to the metacestode in human $\mathrm{AE}$ patients (Hübner et al. 2006). Instead, the production of IFN $\gamma$ and the expression of CD28 on CD4 + T cells were increased in PBMC from $\mathrm{AE}$ patients when compared to controls. This was accompanied by a higher release of the Th2-type chemokine CCL22 (macrophage derived chemokine, MDC) supporting that E. multilocularis also generates proinflammatory immune responses. These results indicate that $E$. multilocularis antigens modulated both, regulatory and inflammatory, Th1 and $\mathrm{Th} 2$ cytokines and chemokines.

Sako et al. (2007) isolated two cDNA clones from E. multilocularis metacestodes encoding cysteine peptidases (EmCLP1 and EmCLP2). The authors showed that EmCLP1 and EmCLP2 are capable of degrading a variety of proteins, including components of the extracellular matrix, albumin and also $\mathrm{IgG}$. The degradation of $\mathrm{IgG}$ appeared to interfere with the cytotoxic activity of infiltrating neutrophils and macrophages. These cells were attracted by IL- 8 and $\mathrm{MCP}-1$, respectively, following activation in vitro of PMN and PBMC from AE patients by parasite vesicles. Such production of chemokines in the presence of specific antibodies may not enhance cellular attacks on the parasite, but stimulate further emigration of effector cells into the inflammatory lesions surrounding proliferating $E$. multilocularis metacestodes (Dreweck et al. 1999). The degradation of humoral molecules might be closely related to the pathogenesis of intrahepatic AE. It has also been shown that the metacestode development in the murine liver is triggered by cell signaling originating from the intermediate host (Brehm et al. 2006). The phosphorylation of EmMPK1, a parasitic orthologue of the extracellular signal-regulated kinase (ERK) MAPK, is specifically induced in in vitro cultured E. multilocularis metacestode vesicles, in response to exogenous host serum, hepatic cells and/or human epidermal growth factor (EGF). The E. multilocularis metacestode is thus able to 'sense' host factors which results in an activation of the parasite MAPK cascade (Spiliotis et al. 2006). The fact the intrahepatic metacestode expresses signaling systems with significant homologies to those of the host raises the interesting question whether cross-communication between cytokines and corresponding receptors of host and parasite can occur during an infection, i.e. whether the parasite may also influence signaling mechanisms of host cells through the secretion of various molecules that might bind to host cell surface receptors. Such interactions could contribute to immunomodulatory activities of E. multilocularis or be involved in mechanisms of organotropism and/or in host tissue destruction or regeneration during parasitic development. Lin et al. (2009) have recently described three mitogenactivated protein kinases (MAPKs), namely p38, JNK and ERK1/2, that become activated in primary cultures of rat hepatocytes upon exposure to metacestode vesicle fluid. JNK activation by host-free supernatant of $E$. multilocularis cultures suggested that liver cell signaling pathways are actually activated by parasitic components. Hepatic proliferation in $\mathrm{AE}$ could thus be induced through a direct influence of the parasite and not only linked to the usual reaction of hepatic cells to the occupying process that takes place in the liver (Lin et al. 2009).

One prominent pathway in the cross-talk between E. multilocularis metacestodes in infected tissues and the immune effector cells involves the activating killer cell lectin-like receptor (NKG2D) and its ligands (major histocompatability complex class I chain-related molecules $\mathrm{A}$ and $\mathrm{B}[\mathrm{MICA} / \mathrm{B}]$ and UL16-binding proteins) (Bahram, 2000; Groh et al. 2001). The germinal layer of the parasite and especially its inner germinal layer, demonstrated strong staining with the anti-MICA/B Mab, implying its presence within these compartments. Hepatic cells of the liver parenchyma surrounding the metacestode expressed MICA/B, even in areas distant from the parasitic vesicles. Because parasite and host cells expressed high amounts of MICA/B proteins, they represent putative targets of liver-infiltrating $\mathrm{CD} 8+\mathrm{T}$ cells and/or NK cells that constitutively express NKG2D on their surface. The strong expression of $\mathrm{MICA} / \mathrm{B}$ in the liver of $\mathrm{AE}$ patients contrasted with the low number of NK cells and the lack of NKG2D expression on the numerous CD8 + $\mathrm{T}$ lymphocytes of the periparasitic infiltrate (Zhang et al. 2008). Some conventional cancer patients presented elevated levels of tumour-derived soluble MICA in their serum (Jinushi et al. 2005). This soluble MICA reduced surface expression of NKG2D and impaired NK and CD8 $+\mathrm{T}$ cell functions (Holdenrieder et al. 2006). Sustained expression of NKG2D ligands on tissue targets could also down-regulate surface expression of NKG2D and reduce general cytotoxicity (Doubrovina et al. 2003; Wu et al. 2005). Therefore, although soluble MICA was absent in the serum of AE patients, the strong sustained expression of MICA/B molecules by $E$. multilocularis metacestodes and host cells might lead to down-regulation of NKG2D, with subsequent inhibition of NKG2D-dependent CD8 + T cell-mediated cytotoxicity. This could contribute to the sustained growth of the parasite. Additionally, TGF- $\beta$, present in most T cells of the granuloma, down-regulate surface expression of 
NKG2D and contribute to the reduction of general cytotoxicity. In previous studies, TGF- $\beta$ has been shown to down-regulate expression of NKG2D in cancer patients, thereby impairing NKG2Dmediated immune surveillance and mediating immune escape of tumours (Castriconi et al. 2003). It would not be surprising if similar events occur in AE.

\section{PROSPECTIVESTUDIES AND APPLICATION}

The elucidation of the peritoneal cytokine profile characterizing the chronic infection mode of murine $\mathrm{AE}$ is crucial to explain some mechanisms behind the impairment of the immune response against the infective larval stage of $E$. multilocularis. The role of DCs, known to orchestrate the immune response, needs to be understood in more detail. Therefore, one needs to address the question whether peritoneal DCs are activated by monitoring their abundance and gene expression levels of cytokines such as TGF$\beta$, IL-10 and IL-12 following AE-infection. It has been previously shown that immature DCs did not mature upon exposure to unfractionated crude metacestode antigen of $E$. multilocularis (Jenne et al. 2001), and lymphocytes in periparasitic infiltrates of AE-infected liver strongly expressed TGF- $\beta$, a pleitropic immunosuppressive cytokine (Zhang et al. 2008). TGF- $\beta$ is able to attenuate CIITA gene expression and consequently inhibits HLA-DRA expression. Moreover, it inhibits the expression of co-stimulatory molecules CD80, CD86 and CD40 on APCs (Rojas et al. 1999). Therefore, one needs to study the integrity of the pathway used by MHC class II molecules within the AE-DCs and the formation of MHC class II-peptide complexes on the surface of AE-DCs, providing the first signal following recognition by $\mathrm{CD} 4+\mathrm{T}$ helper cells (Germain, 1994). The gene expression levels of the different molecules implicated in the formation of MHC class II-peptides complexes, including CIITA, I-a $\beta$ chain, invariant chain (li), non classical class II molecule (H-2M) and cathepsin S enzyme (Cat-S) (Weenink et al. 1997) have to be assessed as well. Studies on the phenotype, in particular the surface expression of co-stimulatory molecules such as B7-1, B7-2 and CD40, will show whether AE-DCs provide the secondary signal required for $\mathrm{T}$ cell activation.

Several subpopulations of regulatory $\mathrm{T}$ cells have been described in other infection models, including suppressive CD8 + T cells (Honey, 2005), two types of regulatory T cells ( $\mathrm{Tr} 1$ ) and T helper 3 (Th3) that might be induced at the mucosal surface to maintain tolerance. Both of them mediated regulation by secretion of soluble factors IL-10 (Tr1) and/or TGF- $\beta$ (Th3). These regulatory cells were often found within the intestinal mucosa (Groux et al. 1997; Faria and Weiner, 2005). Another key regulatory $\mathrm{T}$ cell is the natural CD $4+\mathrm{CD} 25+\mathrm{T}$ cell. These cells express Foxp3, a transcription factor protein that inhibits IL-2 production (Hori et al. 2003; Ghiringhelli et al. 2005). Herein it will interesting to investigate the generation and implication of regulatory $\mathrm{CD} 4+$ and $\mathrm{CD} 8+\mathrm{T}$ cells in the suppression of the immune response of AE-infected mice. As it had already been reported that naïve CD $4+\mathrm{CD} 25+$ $\mathrm{T}$ cells do not proliferate unless supplemented with IL-2 or IL-4, the Th2 immune response, characterized by high expression levels of IL-4, provides, in the presence of TGF- $\beta$, favourable conditions to promote the propagation of regulatory AECD4 + CD25 + p'T cells. To clarify this issue, it will be interesting to determine the proportion of $\mathrm{CD} 4+\mathrm{CD} 25+\mathrm{reg} \mathrm{T}$ cells in the peritoneal cavity of AE-infected mice, and to elucidate whether these cells produce TGF- $\beta$.

We can by no means provide a complete picture of the range of molecules that may be produced by the E. multilocularis metacestode with the potential to modulate immune responses. It is assumed commonly that the production of such molecules serves to facilitate the growth and survival of the parasite. For example, the induction of TGF- $\beta$ may serve two functions. Internal maturation of the metacestode tissue might depend on signaling through a TGF- $\beta$ receptor, although this cytokine can also modulate the host immune response.

In terms of application of these findings to human $\mathrm{AE}$, increasing our knowledge on how the parasite modulates the host immune response is crucially linked to the identification and mechanistic understanding of those parasite and host factors that interact with each other, serve in functions such as host-parasite communication, immunological crosstalk, and metacestode growth and proliferation. These are the metabolites that determine whether an infection leads to survival or death, and they represent a crucial prerequisite for the development of novel immunotherapeutic tools. Such tools could be applied for either prevention of infection and/or disease at an early stage of infection, or for the elimination of established infections, possibly in combination with appropriate chemotherapeutical measures.

\section{ACKNOWLEDGMENTS}

This work was supported by the Swiss National Science Foundation (grant no. 31-111780/1). We kindly acknowledge the invaluable intellectual and experimental support provided by so many collaborative colleagues, which we can not all list here by names.

\section{REFERENCES}

Abbas, A. K., Murphy, K. M. and Sher, A. (1996). Functional diversity of helper T lymphocytes. Nature 383, 787-793.

Amiot, F., Vuong, P., Defontaines, M., Pater, C., Dautry, F. and Uance, M. (1999). Secondary alveolar 
echinococcosis in lymphotoxinalpha and tumour necrosis factor-alpha deficient mice: exacerbation of Echinococcus multilocularis larval growth is associated with cellular changes in the periparasitic granuloma. Parasite Immunology 21, 475-483.

Andrade, M. A., Siles-Lucas, M., Espinoza, E., Pérez Arellano, J. L., Gottstein, B. and Muro, A. (2004). Echinococcus multilocularis laminated-layer components and the E14t 14-3-3 recombinant protein decrease activated rat macrophages $\mathrm{NO}$ production in vitro. Nitric Oxide 10, 150-155.

Auer, H., Hermentin, K. and Aspöck, H. (1988). Demonstration of a specific Echinococcus multilocularis antigen in the supernatant of in vitro maintained protoscolices. Zentralblatt für Bakteriologie und Mikrobiologie, Hyg A 268, 416-423.

Aumüller, E., Schramm, G., Gronow, A., Brehm, K., Gibbs, B. F., Doenhoff, M. J. and Haas, H. (2004). Echinococcus multilocularis metacestode extract triggers human basophils to release interleukin-4. Parasite Immunology 26, 387-395.

Bahram, S. (2000). MIC genes: from genetics to biology. Advances in Immunology 76, 1-60.

Baz, A., Ettlin, G. M. and Dematteis, S. (2006). Complexity and function of cytokine responses in experimental infection by Echinococcus granulosus. Immunobiology 211, 3-9.

Boonstra, A., Asselin-Pature1, C., Gilliet, M., Crain, C., Trinchieri, G., Liu, Y. J. and O'Garra, A. (2003). Flexibility of mouse classical and plasmacytoid-derived dendritic cells in directing $\mathrm{T}$ helper type 1 and 2 cell development: dependency on antigen dose and differential toll-like receptor ligation. Fournal of Experimental Medicine 197, 101-109.

Brehm, K., Spiliotis, M., Zavala-Góngora, R., Konrad, C. and Frosch, M. (2006). The molecular mechanisms of larval cestode development: first steps into an unknown world. Parasitology International 55 (Suppl.), S15-S21.

Bresson-Hadni, S., Koch, S., Miguet, J. P., Gillet, M., Mantion, G. A., Heyd, B. and Vuitton, D. A. (2003). European group of clinicians. Indications and results of liver transplantation for Echinococcus alveolar infection: an overview. Langenbecks Archive of Surgery 388, 231-238.

Bresson-Hadni, S., Liance, M., Meyer, J. P., Houin, R., Bresson, J. L. and Vuitton, D. A. (1990). Cellular immunity in experimental Echinococcus multilocularis infection. II. Sequential and comparative phenotypic study of the periparasitic mononuclear cells in resistant and sensitive mice. Clinical and Experimental Immunology 82, 378-383.

Burden, D. J., Bland, A. P., Hammet, N. C. and Hughes, D. L. (1983). Fasciola hepatica: migration of newly excysted juveniles in resistant rats. Experimental Parasitology 56, 277-288.

Castriconi, R., Cantoni, C., Della Chiesa, M., Vitale, M., Marcenaro, E., Conte, R., Biassoni, R., Bottino, C., Moretta, L. and Moretta, A. (2003). Transforming growth factor beta 1 inhibits expression of NKp30 and NKG2D receptors: consequences for the NK-mediated killing of dendritic cells. Proceedings of the National Academy of Sciences, USA 100, $4120-4125$.
Cox, D. A., Marshall-Clarke, S. and Dixon, J. B. (1989). Activation of normal murine B cells by Echinococcus granulosus. Immunology 67, 16-20.

Dai, W. J. and Gottstein, B. (1999). Nitric oxidemediated immunosuppression following murine Echinococcus multilocularis infection. Immunology 97, 107-116.

Dai, W. J., Hemphill, A., Waldvogel, A., Ingold, K., Deplazes, P., Mossmann, H. and Gottstein, B. (2001). Major carbohydrate antigen of Echinococcus multilocularis induces an immunoglobulin $\mathrm{G}$ response independent of alphabeta $+\mathrm{CD} 4+\mathrm{T}$ cells. Infection and Immunity 69, 6074-6083.

Dai, W. J., Waldvogel, A., Jungi, T., Stettler, M. and Gottstein, B. (2003). Inducible nitric oxide synthasedeficiency in mice increases resistance to chronic infection with Echinococcus multilocularis. Immunology 10, 238-244.

Dai, W. J., Waldvogel, A., Siles-Lucas, M. and Gottstein, B. (2004). Echinococcus multilocularis proliferation in mice and respective parasite 14-3-3 gene expression is mainly controlled by an alphabeta CD4 $\mathrm{T}$-cell-mediated immune response. Immunology 112, 481-488.

Devouge, M. and Ali-Khan, Z. (1983). Intraperitoneal murine alveolar hydatidosis: relationship between the size of the larval cyst mass, immigrant inflammatory cells, splenomegaly and thymus involution. Tropenmedizin und Parasitologie 34, 15-20.

Doubrovina, E. S., Doubrovin, M. M., Vider, E., Sisson, R. B., O'Reilly, R. J., Dupont, B. and Vyas, Y. M. (2003). Evasion from NK cell immunity by MHC class I chain-related molecules expressing colon adenocarcinoma. Fournal of Immunology 171, 6891-6899.

Dreweck, C. M., Soboslay, P. T., Schulz-Key, H., Gottstein, B. and Kern, P. (1999). Cytokine and chemokine secretion by human peripheral blood cells in response to viable Echinococcus multilocularis metacestode vesicles. Parasite Immunology 21, 433-438.

Emery, I., Leclerc, C., Sengphommachanh, K., Vuitton, D. A. and Liance, M. (1998). In vivo treatment with recombinant IL-12 protects C57BL/6J mice against secondary alveolar echinococcosis. Parasite Immunology 20, 81-91.

Emery, I., Liance, M., Deriaud, E., Vuitton, D. A., Houin, R. and Leclerc, C. (1996). Characterization of T-cell immune responses of Echinococcus multilocularis-infected C57BL/6J mice. Parasite Immunology 18, 463-472.

Falcone, F. H., Dahinden, C. A., Gibbs, B. F., Noll, T., Amon, U., Hebestreit, H., Abrahamsen, O., Klaucke, J., Schlaak, M. and Haas, H. (1996). Human basophils release interleukin-4 after stimulation with Schistosoma mansoni egg antigen. European Fournal of Immunology 26, 1147-1155.

Fallon, P. G., Ballantyne, S. J., Mangan, N. E., Barlow, J. L., Dasvarma, A., Hewett, D. R., McIlgorm, A., Jolin, H. E. and McKenzie, A. N. (2006). Identification of an interleukin (IL)-25dependent cell population that provides IL-4, IL-5, and IL-13 at the onset of helminth expulsion. Fournal of Experimental Medicine 203, 1105-1116. 
Faria, A. M. and Weiner, H. L. (2005). Oral tolerance. Immunological Reviews 206, 232-259.

Fort, M. M., Cheung, J., Yen, D., Li, J., Zurawski, S. M., Lo, S., Menon, S., Clifford, T., Hunte, B., Lesley, R., Muchamuel, T., Hurst, S. D., Zurawski, G., Leach, M. W., Gorman, D. M. and Rennick, D. M. (2001). IL-25 induces IL-4, IL-5, and IL-13 and Th2-associated pathologies in vivo. Immunity 15, 985-995.

Foti, M., Granucci, F., Pelizzola, M., Beretta, O. and Ricciardi-Castagnoli, P. (2006). Dendritic cells in pathogen recognition and induction of immune responses: a functional genomics approach. Fournal of Leukocyte Biology 79, 913-916.

Frosch, P. M., Frosch, M., Pfister, T., Schaad, V. and Bitter-Suermann, D. (1991). Cloning and characterization an immunodominant major surface antigen of Echinococcus multilocularis. Molecular and Biochemical Parasitology 48, 121-130.

Gauci, C., Merli, M., Muller, V., Chow, C., Yagi, K., Mackenstedt, U. and Lightowlers, M. W. (2002). Molecular cloning of a vaccine antigen against infection with the larval stage of Echinococcus multilocularis. Infection and Immunity 70, 3969-3972.

Germain, R. N. (1994). MHC-dependent antigen processing and peptide presentation: providing ligands for T lymphocyte activation. Cell 76, 287-299.

Ghiringhelli, F., Puig, P. E., Roux, S., Parcellier, A., Schmitt, E., Solary, E., Kroemer, G., Martin, F., Chauffert, B. and Zitvogel, L. (2005). Tumor cells convert immature myeloid dendritic cells into TGFbeta-secreting cells inducing CD4 $+\mathrm{CD} 25+$ regulatory $\mathrm{T}$ cell proliferation. Fournal of Experimental Medicine 202, 919-929.

Godot, V., Harraga, S., Beurton, I., Deschaseaux, M., Sarciron, E., Gottstein, B. and Vuitton, D. A. (2000). Resistance/susceptibility to Echinococcus multilocularis infection and cytokine profile in humans. I. Comparison of patients with progressive and abortive lesions. Clinical Experimental Immunology 121, 484-490.

Godot, V., Harraga, S., Deschaseaux, M., BressonHadni, S., Gottstein, B., Emilie, D. and Vuitton, D. A. (1997). Increased basal production of interleukin10 by peripheral blood mononuclear cells in human alveolar echinococcosis. European Cytokine Network 8, 401-408.

Godot, V., Harraga, S., Podoprigora, G., Liance, M., Bardonnet, K. and Vuitton, D. A. (2003). IFN alpha-2a protects mice against a helminth infection of the liver and modulates immune responses. Gastroenterology 124, 1441-1450.

Gottstein, B., Dai, W. J., Walker, M., Stettler, M., Muller, N. and Hemphill, A. (2002). An intact laminated layer is important for the establishment of secondary Echinococcus multilocularis infection. Parasitology Research 88, 822-828.

Gottstein, B., Saucy, F., Deplazes, P., Reichen, J., Demierre, G., Zürcher, C., Busato, A. and Pugin, P. (2001). Is a high prevalence of Echinococcus multilocularis in wild and domestic animals associated with increased disease incidence in humans? Emerging Infectious Diseases 7, 408-412.

Gottstein, B., Dai, W. J., Walker, M., Stettler, M., Muller, N. and Hemphill, A. (1992). An intact laminated layer is important for the establishment of secondary Echinococcus multilocularis infection.

Parasitology Research 88, 822-828.

Gottstein, B. and Hemphill, A. (2008). Echinococcus multilocularis: the parasite-host interplay. Experimental Parasitology 119, 447-452.

Groh, V., Rhinehart, R., Randolph-Habecker, J., Topp, M. S., Riddell, S. R. and Spies, T. (2001). Costimulation of CD $8 \alpha \beta$ T cells by NKG2D via engagement by MIC induced on virus-infected cells. Nature Immunology 2, 255-260.

Groux, H., O'Garra, A., Bigler, M., Rouleau, M., Antonenko, S., de Vries, J. E. and Roncarolo, M. G. (1997). A CD4 ${ }^{+}$T-cell subset inhibits antigen-specific $\mathrm{T}$-cell responses and prevents colitis. Nature $\mathbf{3 8 9}$, 737-742.

Holdenrieder, S., Stieber, P., Peterfi, A., Nagel, D., Steinle, A. and Salih, H. R. (2006). Soluble MICA in malignant diseases. International Fournal of Cancer 118, 684-687.

Honey, K. (2005). Immunotherapy: CD8 ${ }^{+} \mathrm{CD} 25^{+}$ regulatory $\mathrm{T}$ cells get the $\mathrm{OK}$. Nature Reviews Immunology 5, 832-833.

Hori, S., Nomura, T. and Sakaguchi, S. (2003). Control of regulatory $\mathrm{T}$ cell development by the transcription factor Foxp3. Science 299, 1030-1031.

Hübner, M. P., Manfras, B. J., Margos, M. C., Eiffler, D., Hoffmann, W. H., Schulz-Key, H., Kern, P. and Soboslay, P. T. (2006). Echinococcus multilocularis metacestodes modulate cellular cytokine and chemokine release by peripheral blood mononuclear cells in alveolar echinococcosis patients. Clinical and Experimental Immunology 145, 243-251.

Huelsmeier, A. J., Gehrig, P. M., Geyer, R., Sack, R., Gottstein, B., Deplazes, P. and Kohler, P. (2002). A major Echinococcus multilocularis antigen is a mucin-type glycoprotein. Fournal of Biological Chemistry 277, 5742-5748.

Ingold, K., Gottstein, B. and Hemphill, A. (1998). Identification of a laminated layer-associated protein in Echinococcus multilocularis metacestodes. Parasitology 116, 363-372.

Ingold, K., Gottstein, B. and Hemphill, A. (2000). High molecular mass glycans are major structural elements associated with the laminated layer of in vitro cultivated Echinococcus multilocularis metacestodes. International Fournal for Parasitology 30, 207-214.

Ito, A., Schantz, P. M. and Wilson, J. F. (1995). Em18, a new serodiagnostic marker for differentiation of active and inactive cases of alveolar hydatid disease. American Fournal of Tropical Medicine and Hygiene 52, 41-44.

Jenkins, P., Dixon, J. B., Rakha, N. K. and Carter, S. D. (1990). Regulation of macrophage-mediated larvicidal activity in Echinococcus granulosus and Mesocestoides corti (Cestoda) infection in mice. Parasitology 100, 309-315.

Jenne, L., Arrighi, J. F., Sauter, B. and Kern, P. (2001). Dendritic cells pulsed with unfractionated helminthic proteins to generate antiparasitic cytotoxic $\mathrm{T}$ lymphocyte. Parasite Immunology 23, 195-201.

Jenne, L., Kilwinski, J., Radloff, P., Flick, W. and Kern, P. (1998). Clinical efficacy of and immunologic alterations caused by interferon gamma therapy for 
alveolar echinococcosis. Clinical Infectious Diseases 26, 492-494.

Jinushi, M., Takehara, T., Tatsumi, T., Hiramatsu, N., Sakamori, R., Yamaguchi, S. and Hayashi, N. (2005). Impairment of natural killer cell and dendritic cell functions by the soluble form of MHC class I-related chain A in advanced human hepatocellular carcinomas. Fournal of Hepatology 43, 1013-1020.

Kilwinski, J., Jenne, L., Jellen-Ritter, A., Radloff, P., Flick, W. and Kern, P. (1999). T lymphocyte cytokine profile at a single cell level in alveolar echinococcosis. Cytokine 11, 373-381.

Kizaki, T., Kobayashi, S., Ogasawara, K., Day, N. K., Good, R. A. and Onoé, K. (1991). Immune suppression induced by protoscoleces of Echinococcus multilocularis in mice. Evidence for the presence of CD8dull suppressor cells in spleens of mice intraperitoneally infected with E. multilocularis. Fournal of Immunology 147, 1659-1666.

Kizaki, T., Ishige, M., Bingyan, W., Day, N. K., Good, R. A. and Onoe, K. (1993). Generation of CD8 + suppressor $\mathrm{T}$ cells by protoscoleces of Echinococcus multilocularis in vitro. Immunology 79, 412-417.

Kocherscheidt, L., Flakowski, A. K., Grüner, B., Hamm, D. M., Dietz, K., Kern, P. and Soboslay, P. T. (2008). Echinococcus multilocularis: inflammatory and regulatory chemokine responses in patients with progressive, stable and cured alveolar echinococcosis. Experimental Parasitology 119, 467-474.

Kouguchi, H., Matsumoto, J., Katoh, Y., Oku, Y., Suzuki, T. and Yagi, K. (2007). The vaccination potential of EMY162 antigen against Echinococcus multilocularis infection. Biochemical and Biophysical Research Communications 363, 915-920.

Koizumi, A., Hada, N., Kaburaki, A., Yamano, K., Schweizer, F. and Takeda, T. (2009). Synthetic studies on the carbohydrate moiety of the antigen from the parasite Echinococcus multilocularis. Carbohydrate Research 344, 856-868.

Korkmaz, M., Inceboz, T., Celebi, F., Babaoglu, A. and Uner, A. (2004). Use of two sensitive and specific immunoblot markers, em70 and em90, for diagnosis of alveolar echinococcosis. Fournal of Clinical Microbiology 42, 3350-3352.

Liance, M., Aicard-Blum, S., Emery, I., Houin, A. and Vuitton, D. A. (1998). Echinococcus multilocularis infection in mice: in vivo treatment with a low dose of IFN-gamma decreases metacestode growth and liver fibrogenesis. Parasite 5, 231-237.

Lin, R. Y., Wang, J. H., Lu, X. M., Zhou, X. T., Mantion, G., Wen, H., Vuitton, D. A. and Richert, L. (2009). Components of the mitogen-activated protein kinase cascade are activated in hepatic cells by Echinococcus multilocularis metacestode. World fournal of Gastroenterology 15, 2116-2124.

MacDonald, A. S., Straw, A. D., Bauman, B. and Pearce, E. J. (2001). CD8 - dendritic cell activation status plays an integral role in influencing Th2 response development. Fournal of Immunology 167, 1982-1988.

Machado, E. R., Ueta, M. T., Lourenço, E. V., Anibal, F. F., Sorgi, C. A., Soares, E. G., Roque-Barreira, M. C., Medeiros, A. I. and Faccioli, L. H. (2005). Leukotrienes play a role in the control of parasite burden in murine strongyloidiasis. Fournal of Immunology 175, 3892-3899.

Maizels, R. M., Balic, A., Gomez-Escobar, N., Nair, M., Taylor, M. D. and Allen, J. E. (2004). Helminth parasites-masters of regulation. Immunology Reviews 201, 89-116.

Mbow, M. L., Christe, M., Rutti, B. and Brossard, M. (1994). Absence of acquired resistance to nymphal Ixodes ricinus ticks in BALB/c mice developing cutaneous reactions. Fournal of Parasitology 80, 81-87.

Mejri, N. and Gottstein, B. (2006). Intraperitoneal Echinococcus multilocularis infection in C57BL/6 mice inhibits the up-regulation of B7-1 and B7-2 costimulator expression on peritoneal macrophages and causes failure to enhance peritoneal $\mathrm{T}$ cell activation. Parasite Immunology 28, 373-385.

Mejri, N. and Gottstein, B. (2009). Echinococcus multilocularis metacestode metabolites contain a cysteine protease that digests eotaxin, a CC pro-inflammatory chemokine. Parasitology Research 105, 1253-1260.

Mishra, A., Hogan, S. P., Lee, J. J., Foster, P. S. and Rothenberg, M. E. (1999). Fundamental signals that regulate eosinophil homing to the gastrointestinal tract. Fournal of Clinical Investigations 103, 1719-1727.

Morelli, A. E. and Thomson, A. W. (2007). Tolerogenic dendritic cells and the quest for transplant tolerance. Nature Review in Immunology 7, 610-621.

Müller, N., Gottstein, B., Vogel, M., Flury, K. and Seebeck, T. (1989). Application of a recombinant Echinococcus multilocularis antigen in an ELISA for diagnosis of human alveolar echinococcosis. Molecular and Biochemical Parasitology 36, 151-160.

O’Garra, A. (1998). Cytokines induce the development of functionally heterogeneous $\mathrm{T}$ helper cell subsets. Immunity 8, 275-283.

Ovington, K. S. and Behm, C. A. (1997). The enigmatic eosinophil: investigation of the biological role of eosinophils in parasitic helminth infection. Memorias do Instituto Oswaldo Cruz 2, 93-104.

Persat, F., Bouhours, J.-F., Mojon, M. and Petavy, A.-F. (1992). Glycosphingolipids with Gal beta 1-6Gal sequences in metacestodes of the parasite Echinococcus multilocularis. Fournal of Biological Chemistry 267, 8764-8769.

Persat, F., Vincent, C., Schmitt, D. and Mojon, M. (1996). Inhibition of human peripheral blood mononuclear cell proliferative response by glycosphingolipids from metacestodes of Echinococcus multilocularis. Infection and Immunity 64, 3682-3687.

Pennock, J. L. and Grencis, R. K. (2006). The mast cell and gut nematodes: damage and defence. Chemical Immunology and Allergy 90, 128-140.

Playford, M. C. and Kamiya, M. (1992). Immune response to Echinococcus multilocularis infection in the mouse model. Fapanese Fournal of Veterinary Research 40, 113-130.

Playford, M. C., Ooi, H. K., Oku, Y. and Kamiya, M. (1992). Secondary Echinococcus multilocularis infection in severe combined immunodeficient (scid) mice: biphasic growth of the larval cyst mass. International Fournal for Parasitology 22, 975-982.

Reis e Sousa, C., Sher, A. and Kaye, P. (1999). The role of dendritic cells in the induction and regulation of 
immunity to microbial infection. Current Opinion in Immunology 11, 392-399.

Rigano, R., Buttari, B., De Falco, E., Profumo, E., Ortona, E., Margutti, P., Scottà, C., Teggi, A. and Siracusano, A. (2004). Echinococcus granulosus-specific $\mathrm{T}$-cell lines derived from patients at various clinical stages of cystic echinococcosis. Parasite Immunology 26, 45-52.

Riley, E. M. and Dixon, J. B. (1987). Experimental Echinococcus granulosus infection in mice: immunocytochemical analysis of lymphocyte populations in local lymphoid infections during early infection. Parasitology 94, 523-532.

Rojas, R. E., Balaji, K. N., Subramanian, A. and Boom, W. H. (1999). Regulation of human CD4(+) alpha-beta $\mathrm{T}$-cell-receptor-positive $(\mathrm{TCR}(+))$ and gamma-delta $\mathrm{TCR}(+) \mathrm{T}$-cell responses to Mycobacterium tuberculosis by interleukin-10 and transforming growth factor beta. Infection and Immunity 67, 6461-6472.

Romagnoli, G., Nisini, R., Chiani, P., Mariotti, S., Teloni, R., Cassone, $A$. and Torosantucci, $A$. (2004). The interaction of human dendritic cells with yeast and germ-tube forms of Candida albicans leads to efficient fungal processing, dendritic cell maturation, and acquisition of a Th1 response-promoting function. Fournal of Leukocyte Biology 75, 117-126.

Rutitzky, L. I., Hernandez, H. J., Yim, Y. S., Ricklan, D. E., Finger, E., Mohan, C., Peter, I., Wakeland, E. K. and Stadecker, M. J. (2005). Enhanced egg-induced immunopathology correlates with high IFN-gamma in murine schistosomiasis: identification of two epistatic genetic intervals. Fournal of Immunology 175, 3920-3926.

Sailer, M., Soelder, B., Allerberger, F., Zaknun, D., Feichtinger, H. and Gottstein, B. (1997). Alveolar echinococcosis of the liver in a six-year-old girl with acquired immunodeficiency syndrome. Fournal of Pediatrics 130, 320-323.

Sako, Y., Yamasaki, H., Nakaya, K., Nakao, M. and Ito, A. (2007). Cloning and characterization of cathepsin L-like peptidases of Echinococcus multilocularis metacestodes. Molecular and Biochemical Parasitology 154, 181-189.

Saraswathi, T. R., Nalinkumar, S., Ranganathan, K., Umadevi, R. and Elizabeth, J. (2003). Eosinophils in health and disease. Fournal of Oral Maxillofacial Pathology 7, 31-33.

Sato, C. and Furuya, K. (1994). Isolation and characterization of a diagnostic polysaccharide antigen from larval Echinococcus multilocularis. Fapanese Fournal of Medicine and Science Biology 47, 65-71.

Sher, A., Pearce, E. and Kaye, P. (2003). Shaping the immune response to parasites: role of dendritic cells. Current Opinion Immunology 15, 421-429.

Siles Lucas, M., Felleisen, R. S. J., Hemphill, A., Wilson, W. and Gottstein, B. (1998). Stage-specific expression of the 14-3-3 gene in Echinococcus multilocularis. Molecular and Biochemical Parasitology 91, 281-293.

Siles-Lucas, M. and Gottstein, B. (2003). The 14-3-3 protein: a key molecule in parasites as in other organisms. Trends in Parasitology 19, 575-581.
Siles-Lucas, M., Merli, M., Mackenstedt, U. and Gottstein, B. (2003). The Echinococcus multilocularis 14-3-3 protein protects mice against primary but not secondary alveolar echinococcosis. Vaccine 21, 431-439.

Siracusano, A., Rigano, R., Ortona, E., Profumo, E., Margutti, P., Buttari, B., Delunardo, F. and Teggi, A. (2008). Immunomodulatory mechanisms during Echinococcus granulosus infection. Experimental Parasitology 119, 483-489.

Spiliotis, M., Konrad, C., Gelmedin, V., Tappe, D., Brückner, S., Mösch, H. U. and Brehm, K. (2006). Characterisation of EmMPK1, an ERK-like MAP kinase from Echinococcus multilocularis which is activated in response to human epidermal growth factor. International Fournal for Parasitology 36, 1097-1112.

Sturm, D., Menzel, J., Gottstein, B., Kern, P. (1995). Interleukin-5 is the predominant cytokine produced by peripheral blood - mononuclear cells in alveolar echinococcosis. Infection and Immunity 63, 1688-1697.

Takeda, K., Kaisho, T. and Akira, S. (2003). Toll-like receptors. Annual Review Immunology 21, 335-376.

Thomas, P. G., Carter, M. R., Atochina, O., Da'Dara, A. A., Piskorska, D., McGuire, E. and Harn, D. A. (2003). Maturation of dendritic cell 2 phenotype by a helminth glycan uses a Toll-like receptor 4-dependent mechanism. Fournal of Immunology 171, 5837-5841.

Vogel, M., Gottstein, B., Müller, N. and Seebeck, T. (1988). Expression of a species-specific Echinococcus multilocularis antigen in Escherichia coli. Molecular and Biochemical Parasitology 31, 117-126.

Vuitton, D. A. (2003). The ambiguous role of immunity in echinococcosis : protection of the host or of the parasite? Acta Tropica 85, 119-132.

Walker, M., Baz, A., Dematteis, S., Stettler, M., Gottstein, B., Schaller, J. and Hemphill, A. (2004). Isolation and characterization of a secretory fraction of Echinococcus multilocularis metacestode potentially involved in modulating the host-parasite interface. Infection and Immunity 72, 527-536.

Weenink, S., Averdunk, H., Boston, T., Boswarva, V., Guery, J. C., Adorini, L., Mellins, E., McCluskey, J. and Gautam, A. M. (1997). Impaired antigen presentation by murine I-Ad class II MHC molecules expressed in normal and HLA-DM-defective human B cell lines. International Immunology 9, 889-896.

Wellinghausen, N., Gebert, P. and Kern, P. (1999). Interleukin (IL)-4, IL-10 and IL-12 profile in serum of patients with alveolar echinococcosis. Acta Tropica 73, 165-174.

Whelan, M., Harnett, M. M., Houston, K. M., Patel, V., Harnett, W. and Rigley, K. P. (2000). A filarial nematode-secreted product signals dendritic cells to acquire a phenotype that drives development of Th2 cells. Fournal of Immunology 164, 6453-6460.

Wu, P., Wei, H., Zhang, C., Zhang, J. and Tian, Z. (2005). Regulation of NK cell activation by stimulatory and inhibitory receptors in tumor escape from innate immunity. Frontiers in Bioscience 10, 3132-3142.

Yamaguchi, Y., Hayashi, Y., Sugama, Y., Miura, Y., Kasahara, T., Kitamura, S., Torisu, M., Mita, S., Tominaga, A. and Takatsu, K. (1988). Highly purified murine interleukin 5 (IL-5) stimulates eosinophil function and prolongs in vitro survival. IL-5 as an 
eosinophil chemotactic factor. Fournal of Experimental Medicine 167, 1737-1742.

Zaccone, P., Burton, O. T. and Cooke, A. (2008). Interplay of parasite-driven immune responses and autoimmunity. Trends in Parasitology 24, 35-42.

Zhang, S., Hüe, S., Sène, D., Penfornis, A., Bresson-Hadni, S., Kantelip, B., Caillat-Zucman, S. and Vuitton, D. A. (2008). Expression of major histocompatibility complex class I chain-related molecule A, NKG2D, and transforming growth factor-beta in the liver of humans with alveolar echinococcosis: new actors in the tolerance to parasites? Fournal of Infectious Diseases 197, 1341-1349.

Zingg, W., Renner-Schneiter, E. C., Pauli-Magnus, C., Renner, E. L., van Overbeck, J., Schläpfer, E., Weber, M., Weber, R., Opravil, M., Gottstein, B., Speck, R. F. and the Swiss HIV Cohort Study (2004). Alveolar echinococcosis of the liver in an adult with human immunodeficiency virus type- 1 infection. Infection 32, 299-302. 